\title{
A change of heart
}

\author{
F. M. Zimmermann • E. van Mierlo • A. Meijer • \\ L. R. Dekker
}

Published online: 4 June 2014

(C) The Author(s) 2014. This article is published with open access at Springerlink.com

\section{Rhythm puzzle-answer}

The ECG shows ST elevation in leads I, II, aVL, and V1-V6 representing acute myocardial infarction of the anterolateral wall. Coronary angiogram showed an occlusion of the mid left anterior descending artery (LAD) (Fig. 2). After reperfusion it became clear that the LAD passed over the apex, explaining the ST elevations in the inferior leads.

Most notably, there is a clear ST alternans in all leads. ST alternans has been studied in several fundamental animal studies $[1,2]$. Alternation of action potential duration and amplitude in the ischaemic area causes alternating variation in injury current, underlying the alternation in ST-segment elevation. This phenomenon only occurs during the first few minutes of acute ischaemia, which explains why it is rarely observed in daily practice $[2,3]$. ST alternans is considered a harbinger of ventricular fibrillation $[2,3]$.

Conclusion: acute anterolateral myocardial infarction with ST alternans.

Open Access This article is distributed under the terms of the Creative Commons Attribution License which permits any use, distribution, and reproduction in any medium, provided the original author(s) and the source are credited.

F. M. Zimmermann $(\bowtie) \cdot$ E. van Mierlo $\cdot$ A. Meijer $\cdot$ L. R. Dekker Department of Cardiology, Catharina Hospital Eindhoven, Michelangelolaan 2, 5623 EJ, Eindhoven, the Netherlands e-mail: frederik.zimmermann@cze.nl

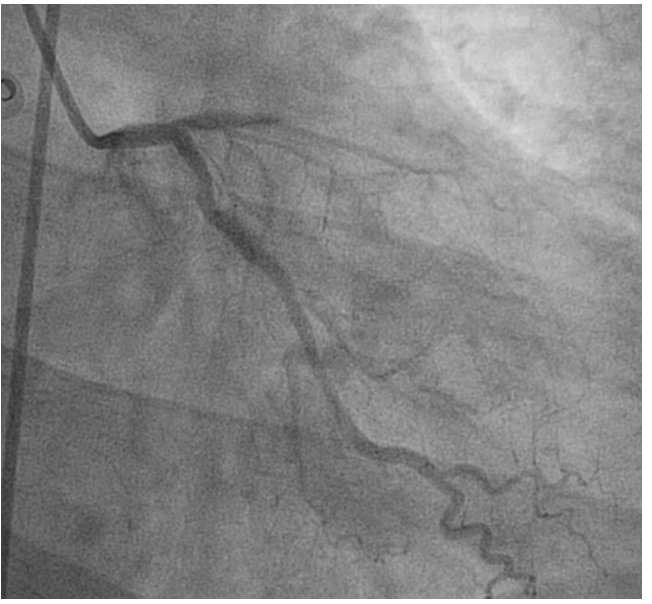

Fig. 2 Occlusion of the mid left anterior descending artery (LAD)

\section{References}

1. Kléber AG, Janse MJ, van Capelle FJ, et al. Mechanism and time course of S-T and T-Q segment changes during acute regional myocardial ischemia in the pig heart determined by extracellular and intracellular recordings. Circ Res. 1978;42: 603-13.

2. Cinca J, Janse MJ, Moréna H, et al. Mechanism and time course of the early electrical changes during acute coronary artery occlusion. Chest. 1980;77(4):499-505.

3. Surawicz B, Fisch C. Cardiac mechanical and electrical alternans. JACC. 1993;20:483-99. 